\title{
Desempenho e qualidade de frutos de tomateiro em cultivo protegido com diferentes números de hastes
}

\author{
Hamilton César de O Charlo; Samuel de C Souza; Renata Castoldi; Leila T Braz \\ UNESP-FCAV, Dep ${ }^{\text {to }}$ Produção Vegetal Rodov. Prof. Paulo Donato Castellane s/n, 14884-900 Jaboticabal-SP; hamiltoncharlo@gmail.com
}

\begin{abstract}
RESUMO
Com o objetivo de avaliar diferentes orientações de crescimento, em tomateiro cultivado sob ambiente protegido, e seus efeitos sobre a produtividade e qualidade, foi conduzido um experimento em casa de vegetação, em solo preparado de acordo com as recomendações técnicas para a cultura. Adotou-se o espaçamento de 1,0 m entre linhas por $0,5 \mathrm{~m}$ entre covas. Foi utilizado o delineamento em blocos casualizados com 8 tratamentos e 4 repetições, em esquema fatorial $2 \times 2 \times 2$, sendo dois sistemas de condução (deixando-se apenas uma haste por planta e deixando-se duas hastes por planta); dois sistemas de desbrota (convencional e diferenciada); dois números de plantas por cova (uma e duas plantas por cova). Cada parcela foi constituída de sete plantas, sendo avaliadas as cinco plantas centrais de cada parcela. Na desbrota convencional todos os brotos laterais foram retirados e, na desbrota diferenciada foram deixados os brotos laterais, e nestes um rácemo. Foram avaliados o número de rácemos por planta, altura do primeiro rácemo, número de frutos por planta, diâmetro e comprimento dos frutos, espessura da polpa, massa dos frutos, número de lóculos por fruto, diâmetro do lóculo, produção estimada total e comercial, $\mathrm{pH}$, acidez titulável, sólidos solúveis e vitamina C. Para as condições em que o trabalho foi conduzido e com base nos resultados obtidos recomenda-se a condução de duas plantas por cova, duas hastes por planta e desbrota do tipo convencional.
\end{abstract}

Palavras-chave: Solanum lycopersicum Mill, produtividade, qualidade.

\begin{abstract}
Performance and quality of tomato fruits of Santa Cruz group in greenhouse with different number of stems

An experiment in a greenhouse was conducted to evaluate different orientations of growth of tomato plants, and the effect on productivity. The soil was prepared according to technical recommendations for the culture and soil analysis. Plants were spaced $1.0 \mathrm{~m}$ between rows and $0.5 \mathrm{~m}$ between plants in the line. The experimental design was comprised of a complete randomized block design, with eight treatments and four repetitions, in factorial arrangement of $2 \times 2 \times 2$. Each plot consisted of seven plants, where only the central five plants of each plot were evaluated. Two systems of conduction were used (leaving only one stem per plant and leaving two stems per plant); and two systems of pruning (conventional and differentiated); and two numbers of plants per hollow (one plant per hollow and two plants per hollow). In the conventional pruning all the lateral sprouts were removed and, in the differentiated pruning the lateral sprouts were left, and in these one raceme. We evaluated the number of raceme per plant, height of the first raceme, number of fruits per plant, diameter and length of fruits, thickness of pulp, weight of fruits, number of locules per fruit, diameter of locule, commercial and total yield estimated, $\mathrm{pH}$, titratable acidity, soluble solids and vitamin $\mathrm{C}$. The conduction of two plants per hollow, two stems per plant and conventional pruning type are recommended.
\end{abstract}

(Recebido para publicação em 26 de fevereiro de 2008; aceito em 8 de maio de 2009)

(Received in February 26, 2008; accepted in May 8, 2009)

$\mathrm{O}$ tomateiro (Solanum lycopersicum) originário da América do Sul (Polston \& Anderson, 1999), e está amplamente distribuído pelo mundo inteiro. Caracteriza-se como uma das principais espécies oleráceas, sendo consumido na forma in natura ou industrializado.

Dentre as hortaliças cultivadas no Brasil, o tomateiro é a mais importante, considerando-se os aspectos socioeconômicos (Martins, 1992). De acordo com Agrianual (2007), de 1999 a 2006 a produção nacional de tomate manteve-se praticamente constante, embora tenha ocorrido diminuição na área plantada da ordem de 16,3\%. Com produção anual de cerca de 3,2 milhões de toneladas numa área de pouco mais de 50.000 ha, o Brasil é o nono maior produtor mundial.

De acordo com Filgueira (2003), a pluviosidade excessiva é o fator agroclimático mais prejudicial à tomaticultura, além disso, tem-se também, a elevada umidade relativa do ar, que favorece o aparecimento de doenças fúngicas e bacterianas.

Uma alternativa para a tomaticultura é o cultivo protegido, uma vez que torna possível obter-se boa produtividade, frutos de excelente qualidade e estabilidade de oferta durante o ano (Martins, 1984).

Em casa de vegetação, o tomateiro deve ser tutorado onde práticas culturais como desbrotas, raleios e podas apicais devem ser adotadas (Postingher et al., 1996). A poda é uma das práticas que mais interferem na produção e na qualidade dos frutos desta hortaliça, sendo muito usada em cultivares de crescimento indeterminado. Existem diversos critérios para se efetuar a poda, os quais dependem da cultivar e do uso a que se destinam (Zupolini, 1993).

Diante da grande importância dessa hortaliça e da necessidade de pesquisas sobre sistemas de condução da cultura, este trabalho teve por objetivo avaliar diferentes orientações de crescimento, em tomateiro cultivado sob ambiente protegido, em Jaboticabal-SP.

\section{MATERIAL E MÉTODOS}

O experimento foi conduzido em casa de vegetação, de maio a novembro de 
2006, na UNESP, Câmpus de Jaboticabal. O local está a uma altitude de $614 \mathrm{~m}$, $21^{\circ} 14^{\prime} 05^{\prime \prime}$ de latitude Sul e $48^{\circ} 17^{\prime} 09^{\prime \prime}$ de longitude Oeste. O solo da área foi classificado como sendo Latossolo Vermelho Eutroférrico (Embrapa, 1999).

Utilizou-se do delineamento experimental em blocos casualizados, com oito tratamentos e quatro repetições, em esquema fatorial $2 \times 2 \times 2$, sendo utilizado, dois sistemas de condução (deixandose apenas uma haste por planta e deixando-se duas hastes por planta); dois sistemas de desbrota (desbrota convencional e desbrota diferenciada) e dois números de plantas por cova (uma planta por cova e duas plantas por cova). Cada parcela foi constituída de sete plantas, sendo avaliadas as cinco plantas centrais.

Nos tratamentos que constavam de duas hastes por planta, a segunda haste foi definida como aquela imediatamente abaixo da primeira inflorescência da planta. Para tratamentos de desbrota, na convencional todos os brotos laterais foram retirados e, na diferenciada foram deixados todos os brotos laterais, e nestes um rácemo. Após o surgimento do rácemo, no broto lateral, deixou-se mais uma folha e fez-se a capação do broto. Quando as plantas atingiram dois metros de altura realizou-se a capação.

Foi utilizada a cultivar de tomateiro Alambra $\mathrm{F}_{1}$, a qual apresenta as características: cultivar do grupo Santa Cruz, com a característica "longa vida", plantas uniformes, vigorosas, produtivas, precoces, e de crescimento indeterminado. Os frutos são uniformes com formato globular, de coloração vermelho intenso quando maduros, resistentes ao rachamento concêntrico e radial e pesam acima de 200 gramas. Apresenta resistência a Verticillium dahliae, Fusarium oxysporum, Cladosporium fulvum, Meloidoigyne incognita, $M$. hapla, M. javanica e M. arenaria (Clause Tézier, 2005).

A semeadura foi realizada em $20 \mathrm{de}$ maio de 2006, em bandejas de poliestireno expandido de 128 células piramidais, preenchidas com substrato Plantmax ${ }^{\circledR}$ HT.

O preparo do solo, no interior da casa de vegetação, constou de um destorroamento, feito por enxada rotativa. Foi realizada adubação de plantio mediante análise de solo e as recomendações técnicas para a cultura, conforme Raij et al. (1997).

As mudas foram transplantadas quando apresentavam de 4 a 6 folhas definitivas no espaçamento de $1,00 \mathrm{~m}$ entre linhas de plantio por $0,50 \mathrm{~m}$ entre covas. As plantas foram tutoradas com fitilhos de polietileno, fixados verticalmente em fios de arame, esticados horizontalmente em mourões de madeira. A fixação das plantas ao tutor foi feita por meio do enrolamento do fitilho nos internódios da planta. A condução das plantas foi de acordo com os tratamentos preconizados.

Demais tratos culturais e fitossanitários foram realizados de acordo com o recomendado para a cultura. Foram avaliadas as cinco plantas centrais de cada parcela experimental, tendo início em 27 de setembro de 2006, quando os frutos se apresentavam no início da maturação e estendendo-se até 27 de novembro de 2006. Logo após a colheita, os frutos foram levados ao laboratório para as análises das características de produção.

Foram avaliados o número de rácemos por planta; altura do primeiro racemo (45 dias após o transplante $(\mathrm{cm})$ ); número médio de frutos por planta; diâmetro médio do frutos $(\mathrm{cm})$; comprimento médio dos frutos $(\mathrm{cm})$; espessura média da polpa (mm); massa média dos frutos (g); número médio de lóculos por fruto; diâmetro médio do lóculo (mm); produção estimada total e comercial (t ha $^{-1}$ ); $\mathrm{pH}$ (determinado no extrato do suco de cinco frutos, com auxílio de peagâmetro digital (Ferreria et al., 2006)); acidez titulável (emprego de uma alíquota de $10 \mathrm{ml}$ de suco, ao qual foi adicionado $40 \mathrm{ml}$ de água destilada e três gotas do indicador fenolftaleína alcoólica a $1 \%$; após, titulação com solução de $\mathrm{NaOH} 0,1 \mathrm{~N}$, até o ponto de viragem (\% de ácido cítrico)); sólidos solúveis (uso de refratômetro manual obtendo os valores em $\%$, corrigidos a $20^{\circ} \mathrm{C}$, no suco de cinco frutos por parcela $\left({ }^{\circ} \mathrm{Brix}\right)$ ).

As médias foram submetidas à análise de variância, conforme delineamento proposto e posteriormente comparadas pelo teste de Tukey a 5\% de probabilidade.

\section{RESULTADOS E DISCUSSÃO}

Para a característica número de frutos por planta, observou-se que houve interação entre os fatores número de plantas por cova e número de hastes por planta e também entre os fatores número de plantas por cova e tipo de desbrota (Tabela 1).

Tanto para a condução de uma ou duas plantas por cova verificou-se que a condução de duas hastes por planta de tomateiro proporcionou maior número de frutos por planta, apresentando 70,57 e 46,96 frutos planta ${ }^{-1}$, respectivamente (Tabela 3).

Ressalte-se que a condução de duas plantas por cova apresentou menor número de frutos por planta (39,17 quando orientada com 1 haste e 46,96 quando orientada com duas hastes). Carvalho \& Tessarioli Neto (2005) também verificaram menor número de frutos por planta quando conduzidas com uma haste, em comparação às conduzidas com duas hastes. Isso se deve ao fato de que plantas conduzidas com duas hastes emitem maior número de rácemos e consequentemente produzem maior número de frutos.

Para a interação entre os fatores número de plantas por cova e tipo de desbrota, observou-se maior número de frutos por planta com a condução de uma planta por cova e desbrota do tipo diferenciada (69,3 frutos planta ${ }^{-1}$ ) (Tabela 3).

Para as características produção por planta e massa do fruto não foram verificadas interações significativas entre os fatores (Tabela 1), portanto, estas serão discutidas separadamente.

Para a característica produção por planta, observou-se diferença significativa para os fatores número de plantas por cova e número de hastes por planta. Já para o fator desbrota não ocorreu diferença significativa (Tabela 1).

Com relação ao fator número de plantas por cova observou-se que a condução de uma planta por cova proporcionou maior produção por planta $(6,61 \mathrm{~kg}$ planta $\left.^{-1}\right)$. Esse fato pode ser explicado pois quando há duas plantas por cova a competição por nutrientes, luz e água, torna-se maior e portanto a produção por planta diminui. 
Tabela 1. Número de frutos por planta (NFP), produção por planta (PP), massa do fruto (MF), sólidos solúveis (SS), pH, teores de vitamina $\mathrm{C}$ (Vit C) e acidez titúlavel (AT), para a cultura do tomateiro, conduzido com diferentes orientações de crescimento (number of fruit per plant (NFP), production per plant (PP) and weight of the fruit (MF), soluble solids (SS), pH, levels of vitamin C (Vit C) and titratable acidity (AT), for the tomato cultivation, conducted with different orientations of growth. Jaboticabal, UNESP, 2007.

\begin{tabular}{|c|c|c|c|c|c|c|c|}
\hline $\begin{array}{l}\text { Plantas/cova } \\
\text { (Pc) }\end{array}$ & NFP & $\begin{array}{c}\text { PP } \\
(\text { kg planta-1) }\end{array}$ & $\begin{array}{l}\text { MF } \\
(g)\end{array}$ & $\begin{array}{l}\text { SS } \\
\left({ }^{\circ} \mathrm{Brix}\right)\end{array}$ & $\mathrm{pH}$ & 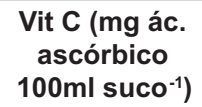 & $\begin{array}{c}\text { AT } \\
(\% \text { ac. cítrico) }\end{array}$ \\
\hline 1 & 61,73 a & $6,61 \mathrm{a}$ & 109,35 a & $4,94 \mathrm{a}$ & $4,28 a$ & $18,30 \mathrm{a}$ & $0,20 a$ \\
\hline 2 & $43,07 \mathrm{~b}$ & $4,02 \mathrm{~b}$ & $97,81 \mathrm{~b}$ & $4,92 \mathrm{a}$ & $4,27 \mathrm{a}$ & $18,26 \mathrm{a}$ & $0,18 \mathrm{a}$ \\
\hline \multicolumn{8}{|c|}{$\mathrm{N}^{\circ}$ de hastes $(\mathrm{H})$} \\
\hline 1 & $46,03 \mathrm{~b}$ & $4,92 \mathrm{~b}$ & 110,36 a & $4,91 \mathrm{a}$ & $4,28 a$ & 18,15 a & $0,20 \mathrm{a}$ \\
\hline 2 & $58,76 \mathrm{a}$ & $5,71 \mathrm{a}$ & $96,79 \mathrm{~b}$ & $4,95 \mathrm{a}$ & $4,27 \mathrm{a}$ & $18,42 \mathrm{a}$ & $0,18 \mathrm{~b}$ \\
\hline \multicolumn{8}{|l|}{ Desbrota (Db) } \\
\hline Diferenciada & $57,71 \mathrm{a}$ & $5,50 a$ & $95,24 \mathrm{~b}$ & $5,00 \mathrm{a}$ & $4,27 a$ & $18,38 \mathrm{a}$ & $0,19 a$ \\
\hline Convencional & $47,08 \mathrm{~b}$ & $5,13 a$ & $111,91 \mathrm{a}$ & 4,86 a & $4,28 \mathrm{a}$ & 18,19 a & $0,19 a$ \\
\hline \multicolumn{8}{|l|}{ Interação } \\
\hline $\mathrm{Pc} \times \mathrm{H}$ & 6,19 * & $3,75^{\mathrm{ns}}$ & $0,00 \mathrm{~ns}$ & $0,22 \mathrm{~ns}$ & $0,20 \mathrm{~ns}$ & $2,75^{\text {ns }}$ & 2,68 ns \\
\hline $\mathrm{Pc} \times \mathrm{Db}$ & 5,11 * & $1,15^{\text {ns }}$ & 0,19 ns & 3,27 ns & $0,20 \mathrm{~ns}$ & 0,30 ns & 1,49 ns \\
\hline $\mathrm{H} \times \mathrm{Db}$ & $0,05^{\text {ns }}$ & $1,85^{\mathrm{ns}}$ & 0,62 ns & $1,09 \mathrm{~ns}$ & $0,20 \mathrm{~ns}$ & $0,45^{\text {ns }}$ & 4,39 * \\
\hline $\mathrm{Pc} \times \mathrm{H} \times \mathrm{Db}$ & $3,11^{\mathrm{ns}}$ & 2,31 ns & $0,00 \mathrm{~ns}$ & $6,60 \mathrm{~ns}$ & $2,75^{\mathrm{ns}}$ & 0,30 ns & 1,21 ns \\
\hline $\mathrm{CV}(\%)$ & 10,72 & 10,06 & 5,97 & 3,76 & 0,82 & 9,74 & 14,83 \\
\hline
\end{tabular}

Médias seguidas de letras minúsculas iguais na coluna não diferem estatisticamente entre si pelo teste de Tukey, 5\% de probabilidade (means followed by lowercase letters equal in the column don't differ significantly between them, according to Tukey's test, 5\% probability).

Para o fator número de hastes por planta verificou-se que a maior produção por planta foi observada quando conduzida com duas hastes $(5,71 \mathrm{~kg}$ planta $^{-1}$ ) (Tabela 1). Possivelmente isto deve estar relacionado ao fato de haver maior número de flores e maior área foliar fotossintetizante.

Para a característica massa do fruto verificou-se diferença significativa para todos os fatores avaliados isoladamente. Para o fator número de plantas por cova verificou-se que a condução com uma planta por cova proporcionou massa do fruto superior $(109,35 \mathrm{~g})$ às médias das plantas conduzidas com duas plantas por cova $(97,81 \mathrm{~g})$.

Com relação ao fator número de hastes por planta, observou-se que a maior massa foi proporcionada pelas plantas conduzidas com uma haste (110,36 g), isto porque, plantas conduzidas com uma haste produzem menor quantidade de frutos, o que possibilitou que esses se desenvolvessem mais, devido ao menor número de drenos por planta.

Carvalho \& Tessarioli Neto (2005) verificaram frutos com massas superiores aos observados no presente trabalho. Os referidos autores observaram valores máximos de massa de fruto de 149,24 g para o híbrido Carmen conduzi- do com uma haste, e 109,96 g para o híbrido Diana conduzido com duas hastes por planta. A maior massa de fruto observada pelos referidos autores pode ser atribuído às cultivares utilizadas serem diferentes da utilizada no presente trabalho.

Para o fator tipo de desbrota, observou-se que a desbrota convencional proporcionou massa superior $(111,9 \mathrm{~g})$ à obtida através da desbrota diferenciada $(95,2 \mathrm{~g})$. Essa diferença se deve ao fato de que as plantas conduzidas com a desbrota diferenciada apresentavam maior número de frutos por planta, o que resulta em maior competição pelos fotoassimilados, e conseqüentemente, menor massa de frutos (Tabela 1).

Para as características sólidos solúveis, $\mathrm{pH}$ e teor de vitamina $\mathrm{C}$, não se observou diferenças e interações significativas entre os fatores avaliados. $\mathrm{O}$ teor médio de sólidos solúveis foi de $4,9^{\circ}$ Brix, $\mathrm{pH}$ de 4,3 e vitamina $\mathrm{C}$ de 18,9 mg de ácido ascórbico/100ml de suco (Tabela 1).

Para a característica acidez titulável observou-se interação significativa entre os fatores número de hastes por planta e tipo de desbrota. De acordo com a Tabela 3, observa-se que a condução de uma haste por planta proporcionou maiores teores de acidez titulável, tanto para a condução com desbrota diferenciada, bem como para a desbrota convencional, apresentando 0,22 e 0,19\% de ácido cítrico, respectivamente. Estes valores são inferiores à média de acidez titulável de frutos de tomateiro $(0,42 \%)$ observados por Mattedi et al. (2004a).

Detectaram-se interações significativas entre os fatores avaliados apenas para a característica espessura da polpa (Tabela 2).

Para a característica diâmetro do fruto observou-se diferença significativa para todos os fatores (Tabela 2). Com relação ao fator número de plantas por cova, verificou-se que a condução de uma planta por cova proporcionou frutos com maior diâmetro $(6,6 \mathrm{~cm})$ quando comparado às plantas conduzidas com duas plantas por cova $(6,4 \mathrm{~cm})$.

Quanto ao fator tipo de desbrota, observou-se que plantas conduzidas com desbrota convencional produziram frutos com diâmetro superior $(6,6 \mathrm{~cm})$ ao das plantas conduzidas com a desbrota diferenciada $(6,5 \mathrm{~cm})$ (Tabela 2). Essa diferença provavelmente ocorre devido à menor competição por fotoassimilados nas plantas conduzidas pela desbrota convencional, visto que o número de frutos por planta foi menor. 
Tabela 2. Diâmetro do fruto (DF), comprimento do fruto (CF), diâmetro do lóculo (DL), número de lóculos (NL), espessura da polpa (EP), produção total estimada por hectare (PTEH), produção comercial estimada por hectare (PCEH), número de rácemos por planta (NRP) e a altura do primeiro rácemo (APR), para a cultura do tomateiro conduzido com diferentes orientações de crescimento (diameter of the fruit (DF), length of the fruit (CF), diameter of locule (DL), number of locules (NL), pulp thickness (EP), estimated total production per hectare (PTEH), estimated commercial production per hectare (PCEH), number of racemes per plant (NRP) and height of the first raceme (APR), for the tomatoes culture conducted with different orientations of growth.). Jaboticabal, UNESP, 2007.

\begin{tabular}{|c|c|c|c|c|c|c|c|c|c|}
\hline $\begin{array}{l}\text { Plantas/cova } \\
\text { (Pc) }\end{array}$ & $\begin{array}{l}\text { DF } \\
\text { (cm) }\end{array}$ & $\begin{array}{l}\text { CF } \\
(\mathrm{cm})\end{array}$ & $\begin{array}{c}\text { DL } \\
(\mathrm{mm})\end{array}$ & NL & $\begin{array}{c}\text { EP } \\
(\mathrm{mm})\end{array}$ & $\begin{array}{l}\text { PTEH } \\
\left(\text { t ha-1) }^{-1}\right.\end{array}$ & $\begin{array}{l}\text { PCEH } \\
\left(\mathrm{t} \mathrm{ha}^{-1}\right)\end{array}$ & NRP & $\begin{array}{l}\text { APR } \\
(\mathrm{cm})\end{array}$ \\
\hline 1 & $6,6 \mathrm{a}$ & $5,3 a$ & $18,50 \mathrm{a}$ & 3,50 a & $8,76 \mathrm{a}$ & $132,50 \mathrm{~b}$ & $130,94 \mathrm{~b}$ & 12,79 a & $38,39 a$ \\
\hline 2 & $6,4 \mathrm{~b}$ & $5,1 \mathrm{~b}$ & $18,05 \mathrm{a}$ & 3,60 a & $8,24 \mathrm{~b}$ & $161,15 \mathrm{a}$ & $156,55 \mathrm{a}$ & $10,75 \mathrm{~b}$ & $34,17 \mathrm{a}$ \\
\hline \multicolumn{10}{|l|}{$\mathrm{N}^{\circ}$ hastes $(\mathrm{H})$} \\
\hline 1 & 6,6 a & 5,3 a & 18,27 a & 3,53 a & 8,70 a & $137,00 \mathrm{~b}$ & $135,51 \mathrm{~b}$ & $9,32 \mathrm{~b}$ & $37,87 \mathrm{a}$ \\
\hline 2 & $6,5 \mathrm{a}$ & $5,1 \mathrm{~b}$ & $18,27 \mathrm{a}$ & $3,57 \mathrm{a}$ & $8,31 \mathrm{~b}$ & 156,65 a & $151,97 \mathrm{a}$ & $14,21 \mathrm{a}$ & $34,68 \mathrm{a}$ \\
\hline \multicolumn{10}{|l|}{ Desbrota (Db) } \\
\hline Diferenciada & $6,5 \mathrm{~b}$ & $51,47 \mathrm{~b}$ & $18,08 \mathrm{a}$ & 3,57 a & 8,32 b & 151,22 a & $146,84 \mathrm{a}$ & $13,70 \mathrm{a}$ & $37,78 \mathrm{a}$ \\
\hline Convencional & $6,6 \mathrm{a}$ & 52,57 a & $18,47 \mathrm{a}$ & $3,53 \mathrm{a}$ & $8,68 \mathrm{a}$ & $142,42 \mathrm{~b}$ & $140,65 \mathrm{a}$ & $9,84 \mathrm{~b}$ & $34,78 \mathrm{a}$ \\
\hline \multicolumn{10}{|l|}{ Interação } \\
\hline $\mathrm{Pc} \times \mathrm{H}$ & $1,34^{\mathrm{ns}}$ & $2,87^{\mathrm{ns}}$ & $0,04^{\mathrm{ns}}$ & $0,07^{\text {ns }}$ & 12,53 ** & $0,49^{\mathrm{ns}}$ & $0,00^{\mathrm{ns}}$ & $0,61^{\mathrm{ns}}$ & $0,00^{\mathrm{ns}}$ \\
\hline $\mathrm{Pc} \times \mathrm{Db}$ & $0,89^{\text {ns }}$ & $2,40^{\mathrm{ns}}$ & $4,03^{\text {ns }}$ & $0,07^{\mathrm{ns}}$ & $0,87^{\mathrm{ns}}$ & $0,27^{\text {ns }}$ & $0,00^{n s}$ & $1,81^{\mathrm{ns}}$ & $0,18^{\text {ns }}$ \\
\hline $\mathrm{H} \times \mathrm{Db}$ & $0,05^{\mathrm{ns}}$ & $0,09^{\text {ns }}$ & $0,00^{\mathrm{ns}}$ & $0,87^{\mathrm{ns}}$ & $0,69^{\text {ns }}$ & $1,22^{\text {ns }}$ & $0,17^{\text {ns }}$ & $0,43^{\text {ns }}$ & $0,33^{\text {ns }}$ \\
\hline$\underline{\mathrm{Pc}} \times \mathrm{H} \times \mathrm{Db}$ & $0,15^{\mathrm{ns}}$ & $0,75^{\mathrm{ns}}$ & $0,33^{\text {ns }}$ & $0,87^{\mathrm{ns}}$ & $0,00^{\mathrm{ns}}$ & $1,93^{\mathrm{ns}}$ & $0,36^{\mathrm{ns}}$ & $0,00^{\mathrm{ns}}$ & $0,20^{\mathrm{ns}}$ \\
\hline $\mathrm{CV}(\%)$ & 2,11 & 1,89 & 4,35 & 9,02 & 2,88 & 8,09 & 9,24 & 11,99 & 21,95 \\
\hline
\end{tabular}

Médias seguidas de letras minúsculas iguais na coluna não diferem estatisticamente entre si pelo teste de Tukey, $5 \%$ de probabilidade (means followed by lowercase letters equal in the column don't differ significantly between them, according to Tukey's test, $5 \%$ probability).

Mattedi et al. (2004b) avaliando 16 acessos de tomateiro do Banco de Germoplasma de Hortaliças da UFV e 3 testemunhas (Fanny, Santa Clara e Débora Plus) quanto às características de fruto, verificaram maior diâmetro de fruto para a cultivar Fanny $(8,1 \mathrm{~cm})$, no presente trabalho o maior diâmetro do fruto foi de $6,6 \mathrm{~cm}$, observado nas plantas conduzidas com uma planta por cova.

Para a característica comprimento do fruto, verificou-se diferença significativa em todos os fatores avaliados (Tabela 2). Quanto ao número de plantas por cova, observou-se que a condução de uma planta por cova proporcionou frutos com maior comprimento $(5,3 \mathrm{~cm})$ quando comparado aos produzidos com duas plantas por cova $(5,1 \mathrm{~cm})$.

Para o fator número de hastes por planta, verificou-se que plantas conduzidas com uma haste por planta produziram frutos com comprimento superior $(5,3 \mathrm{~cm})$ às plantas conduzidas com duas hastes por planta $(5,1 \mathrm{~cm})$. A diferença se deve à competição por fotoassimilados entre os frutos, sendo maior em plantas conduzidas com duas hastes.

Quanto ao fator tipo de desbrota, observou-se que plantas conduzidas com a desbrota convencional produziram frutos de maior comprimento $(5,3 \mathrm{~cm})$ que as plantas conduzidas com desbrota diferenciada $(5,1 \mathrm{~cm})$. Mattedi et al. (2004b) avaliando dezesseis genótipos e três cultivares comerciais de tomateiro, observaram valores de comprimento do fruto variando de 2,5 a $6,7 \mathrm{~cm}$, sendo que os valores de comprimento estão bem próximos aos encontrados no presente trabalho.

Para as características diâmetro do lóculo e número de lóculos não houve diferença significativa para os fatores avaliados (Tabela 2).

Para a característica espessura da polpa, observou-se interação somente para os fatores número de plantas por cova e número de hastes por planta. Pelo fato de não haver interação entre o fator desbrota, este será discutido separadamente.

Observou-se diferença significativa para o fator tipo de desbrota, sendo que plantas conduzidas com desbrota convencional produziram frutos com espessura de polpa maior $(8,68 \mathrm{~mm})$ do que plantas conduzidas pelo método de desbrota diferenciada $(8,32 \mathrm{~mm})$.

Observa-se que a condução de uma haste por planta com uma planta por cova proporcionou maior valor de espessura de polpa. Já quando se utilizou duas hastes por planta, recomenda-se uma planta por cova para se obter maiores espessuras de polpa (Tabela 3). Estes valores são semelhantes aos máximos valores de espessura de polpa de frutos de tomateiro $(8,38 \mathrm{~mm})$ observados por Mattedi et al. (2004a).

Para as características produtividade total estimada por hectare e produtividade comercial estimada por hectare não foram detectadas interações significativas entre os fatores avaliados, portanto os dados estão apresentados separadamente.

Para a característica produtividade total estimada verificou-se diferença significativa para todos os fatores avaliados (Tabela 2). Para o fator número de plantas por cova observou-se que a condução de duas plantas por cova apresentou a maior média de produtividade estimada $\left(161,15 \mathrm{t} \mathrm{ha}^{-1}\right)$. Esta produção se deve pelo maior número de plantas por área.

Com relação ao número de hastes por planta, verificou-se que a maior produtividade estimada foi obtida quando a planta foi conduzida com 2 hastes $(156,65$ tha $\left.{ }^{-1}\right)$. 
Tabela 3. Interações significativas entre os fatores avaliados de tomateiros conduzidos com diferentes orientações de crescimento (significant interactions between factors evaluated of tomato culture conducted with differents growth orientations). Jaboticabal, UNESP, 2007.

\begin{tabular}{|c|c|c|c|}
\hline \multicolumn{4}{|c|}{$\begin{array}{l}\text { Número de frutos por planta em função da interação entre número de plantas por } \\
\text { cova e número de hastes por planta }\end{array}$} \\
\hline & 1 haste & 2 hastes & Teste F \\
\hline 1 planta/cova & $52,90 \mathrm{~B} \mathrm{a}$ & $70,57 \mathrm{~A} \mathrm{a}$ & 39,56 ** \\
\hline 2 plantas/cova & $39,17 \mathrm{~B} \mathrm{~b}$ & $46,96 \mathrm{~A} \mathrm{~b}$ & 7,68 * \\
\hline
\end{tabular}

Número de frutos por planta em função da interação entre número de plantas por cova e método de desbrota

\begin{tabular}{lccc}
\hline & Diferenciada & Convencional & Teste $\mathrm{F}$ \\
\cline { 2 - 4 } 2 planta/cova & $69,30 \mathrm{~A} \mathrm{a}$ & $54,17 \mathrm{~B} \mathrm{a}$ & $28,97^{* *}$ \\
\hline
\end{tabular}

Acidez titulável em função da interação entre número de hastes por planta $\mathrm{e}$ método de desbrota em frutos de tomateiro

\begin{tabular}{lccc}
\hline & Diferenciada & Convencional & Teste $\mathrm{F}$ \\
\cline { 2 - 4 } 1 haste/planta & $0,22 \mathrm{Aa}$ & $0,19 \mathrm{Aa}$ & $3,06 \mathrm{n}^{\mathrm{ns}}$ \\
2 hastes/planta & $0,17 \mathrm{Ab}$ & $0,19 \mathrm{Aa}$ & $1,47^{\mathrm{ns}}$ \\
\hline
\end{tabular}

Espessura da polpa em função da interação entre número de plantas por cova e número de hastes por planta de frutos de tomateiro

\begin{tabular}{lccc}
\hline & 1 haste & 2 hastes & Teste $\mathrm{F}$ \\
\cline { 2 - 4 } 1 planta/cova & $8,80 \mathrm{~A} \mathrm{a}$ & $8,72 \mathrm{~A} \mathrm{a}$ & $0,466^{\mathrm{ns}}$ \\
2 plantas/cova & $8,59 \mathrm{~A} \mathrm{a}$ & $7,89 \mathrm{~B} \mathrm{~b}$ & $32,35^{* *}$ \\
\hline
\end{tabular}

Médias seguidas de letras maiúsculas iguais na linha e minúsculas na coluna não diferem estatisticamente pelo teste de Tukey, a 5\% de probabilidade (means followed by capitalization equals in the row and lowercase letters equal in the column don't differ statistically by Tukey's test, $5 \%$ probability).

Carvalho \& Tessarioli Neto (2005), observaram produtividades inferiores às obtidas no presente trabalho. Os referidos autores verificaram produtividades máximas de $110,15 \mathrm{t} \mathrm{ha}^{-1}$ para o híbrido Diana conduzido com duas hastes e 97,78 t ha ${ }^{-1}$ para o híbrido Carmen conduzido com uma haste por planta (Tabela 2).

Observou-se que a desbrota diferenciada proporcionou maior produtividade total estimada $\left(151,22 \mathrm{t} \mathrm{ha}^{-1}\right)$. Isto, provavelmente, está relacionado ao maior número de inflorescências e área foliar das plantas, proporcionando assim, maior produtividade.

Para a característica produtividade comercial estimada por hectare observou-se diferença significativa para os fatores número de plantas por cova e número de hastes por planta. Para o fator número de plantas por cova, verificou-se que a condução de duas plantas por cova proporcionou maior produção comercial estimada $\left(156,55\right.$ tha $\left.^{-1}\right)$ (Tabela 2). Esse resultado se deve ao maior número de plantas por área, quando comparado com a condução de uma planta por cova.
Quanto ao fator número de hastes por planta, observou-se que a maior produtividade comercial estimada foi obtida quando a planta foi conduzida com duas hastes $\left(151,97 \mathrm{t} \mathrm{ha}^{-1}\right)$ (Tabela 2).

Marim et al. (2005) avaliando a eficiência de três sistemas de tutoramento (tradicional, triangular e vertical) e dois tipos de condução (1 e 2 hastes por planta) da planta do tomateiro, na produção de frutos comercializáveis, verificaram produtividades comerciais inferiores às obtidas no presente trabalho, ou seja, produtividades comerciais máximas de $73,4 \mathrm{t} \mathrm{ha}^{-1}$ para plantas tutoradas pelo método tradicional com uma haste por planta, e 70,2 $\mathrm{t} \mathrm{ha}^{-1}$ para plantas tutoradas pelo método vertical com duas hastes por planta, de agosto a dezembro de 2000 . As produtividades comerciais inferiores se devem ao fato de as cultivares utilizadas nos experimentos serem diferentes e também porque os experimentos foram realizados em campo, enquanto no presente trabalho o experimento foi realizado em casa de vegetação.

Para estas características número de rácemos por planta (NRP) e a altura do primeiro rácemo (APR) não detectaramse interações significativas entre os fatores avaliados, portanto os dados estão apresentados separadamente.

Para a característica número de rácemos por planta, observou-se diferença significativa entre os fatores avaliados. Verificou-se que a condução de uma planta por cova proporcionou maior número de rácemos por planta $(12,79)$.

O número de hastes por planta e o tipo de desbrota também influenciaram esta característica, sendo que foi observado maior número de rácemos por planta quando se orientou as plantas com duas hastes $\left(14,21\right.$ rácemos planta $\left.^{-1}\right)$ e com desbrota diferenciada $(13,70$ rácemos planta $\left.^{-1}\right)$, respectivamente.

Para a altura do primeiro rácemo não verificaram-se diferenças significativas entre os fatores avaliados (Tabela 2).

Com base nas características produtivas e qualitativas dos frutos, concluise que para as condições em que o trabalho foi conduzido, o cultivo com duas plantas por cova, duas hastes por planta e desbrota convencional é o mais indicado.

\section{AGRADECIMENTO}

Ao CNPq pela concessão de bolsa de iniciação científica ao segundo autor do trabalho.

\section{REFERÊNCIAS}

AGRIANUAL. 2007. Anuário da agricultura brasileira. São Paulo: FNP Consultoria e Agroinformativo. p. 490-496.

CARVALHO LA; TESSARIOLI NETO J. 2005. Produtividade de tomate em ambiente protegido, em função do espaçamento e número de ramos por planta. Horticultura Brasileira 23: 986989.

CLAUSE TÉZIER. 2006, 27 de março. Tomate. Disponível em www.clausetezier.com.

EMPRESA BRASILEIRA DE PESQUISA AGROPECUÁRIA. Centro Nacional de Pesquisa de Solos. 1999. Sistema brasileiro de classificação de solos: produção de informação. Rio de Janeiro: Embrapa. 412 $\mathrm{p}$.

FERREIRA MMM; FERREIRA GB; FONTES PCR; DANTAS JP. 2006. Qualidade do tomate em função de doses de nitrogênio e da adubação orgânica em duas estações. Horticultura Brasileira 24: 141-145. 
FILGUEIRA FAR. 2003. Novo manual de olericultura: agrotecnologia moderna na produção e comercialização de hortaliças. Viçosa: UFV. $402 \mathrm{p}$.

MARIM BG; SILVA DJH; GUIMARÃES MA; BELFORT G. 2005. Sistemas de tutoramento e condução do tomateiro visando produção de frutos para consumo in natura. Horticultura Brasileira 23: 951955.

MARTINS G. 1984. A produção de tomate em casa de vegetação no Amazonas. Piracicaba: FEALQ. 55 p. (Relatório de pesquisa).

MARTINS G. 1992. Uso de casa de vegetação com cobertura plástica na tomaticultura de verão. Jaboticabal: UNESP-FCAV. $65 \mathrm{p}$ (Tese doutorado).
MATTEDI AP; CALIMAN FRB; MOREIRA GR; SOARES BO; SILVA DJH; GUIMARÃES MA; MARIM BG. 2004a, 08 de maio de 2007. Caracterização e diversidade genética entre acessos de tomateiro do banco de germoplasma de hortaliças da Universidade Federal de Viçosa e cultivares comerciais quanto à qualidade dos frutos. Disponível em http:/ /200.210.234.180/HORTA/Download/ Biblioteca/44_104.pdf.

MATTEDI AP; SOARES BO; MARIM BG; SILVADJH; GUIMARÃES MA; ABREU FB. 2004b, 08 de maio de 2007. Caracterização e diversidade genética diversidade genética entre acessos de tomateiro do banco de germoplasma de hortaliças da UFV em relação a caracteres de fruto. Disponível em http://200.210.234.180/HORTA/ Download/Biblioteca/44_504. pdf.
POLSTON JE; ANDERSON PK. 1999. Surgimiento y distribución de geminivirus transmitidos por mosca blanca em tomate en el Hemisferio Occidental. Manejo Integrado de Plagas y Agroecología 53: 24-42

POSTINGHER D; MARTINS SR; ASSIS FN. 1996. Respostas agronômicas da cultura do tomateiro em estufa plástica. Revista Brasileira de Agrociência, 2: 105-108.

RAIJ BV; CANTARELLA H; QUAGGIO JA; FURLANI AMC (eds.). 1997. Recomendações da adubação e calagem para o Estado de São Paulo. 2. ed. Campinas: IAC. 285 p. (Boletim Técnico 100).

ZUPOLINI SA. 1993. Sistemas de condução em híbridos de tomate de crescimento determinado cultivado em estufa. Jaboticabal: UNESP-FCAV. 56 p. (Monografia graduação). 